\title{
FURNAS DE SOMBRIO COMO UM PATRIMÔNIO CULTURAL LOCAL
}

\author{
FURNAS DE SOMBRIO AS A LOCAL CULTURAL HERITAGE
}

Paola Vieira da Silveira ${ }^{1}$

\section{RESUMO}

O presente texto apresenta As Furnas de Sombrio, um complexo de cinco grutas localizadas na cidade de Sombrio, região Sul de Santa Catarina. O objetivo da pesquisa é mostrar que este bem se caracteriza como um patrimônio histórico-cultural e natural, assim como mostrar a degradação que ele sofre por agentes antrópicos. Para isso foi feito um levantamento bibliográfico de obras locais falando sobre o bem patrimonial em questão e obras sobre preservação de bens culturais e naturais evidenciando que as Furnas de Sombrio devem ser melhores assistidas pelo poder público garantindo uma melhor preservação para desempenhar seu papel de bem cultural.

Palavras-chave: Grutas. Furnas. Santa Catarina. Patrimônio cultural. Religião.

\begin{abstract}
This text presents As Furnas de Sombrio, a complex of five caves located in the city of Sombrio, in the southern region of Santa Catarina. The objective of the research is to show that this property is characterized as a historical-cultural and natural heritage, as well as to show the degradation that it suffers by anthropic agents. For this purpose, a bibliographic survey of local works talking about the heritage property in question and works on the preservation of cultural and natural assets was made, showing that Furnas de Sombrio should be better assisted by the public authorities, ensuring better preservation to perform its role as a cultural asset. .
\end{abstract}

Keywords: Caves. Furnas. Santa Catarina. Cultural heritage. Religion.

\section{INTRODUÇÃO}

Neste texto busca-se apresentar as "Furnas de Sombrio" como patrimônio cultural, suscetível de ser preservado. Furna é como denomina-se cavidades em encostas de rochas, sendo chamada ainda de gruta. A cidade de Sombrio localizada no extremo sul de Santa Catarina, parte da microrregião AMESC (Associação de Municípios do Extremo Sul Catarinense), conta com um agrupamento de grutas uma ao lado da outra, que ficaram popularmente conhecidas como Furnas ou Furnas de Sombrio.

Esse agrupamento tem 4 grutas, algumas fontes como Murara (2000) apontam para cinco. A maior gruta tem dezessete metros de abertura e uma área total de 1.118

\footnotetext{
${ }^{1}$ Historiadora e professora. Mestra em Ciências Ambientais e Esp. em patrimônio cultural.
} 
metros quadrado, já a menor, pouco explorada, até então, encontra-se coberta pela mata fechada, segundo levantamento do jornalista Marcial David Murara (2000). A região conta com muitas belezas naturais que vão de praias à canyons, nesse contexto, Sombrio se faz lembrar, em especial, pelas Furnas, que hoje beiram a BR 101, portanto, é um ponto de fácil acesso e muita movimentação.

Para compreender as Furnas de Sombrio como bem cultural, consideraremos a noção de patrimônio de Carlos Lemos (2010), bem como da constituição brasileira de 1988. A atual constituição traz em seu artigo 216 uma concepção de patrimônio cultural ampla, abrangendo a diversidade de bens culturais. Segundo ela, "constituem patrimônio cultural brasileiro os bens de natureza material e imaterial, tomados individualmente ou em conjunto, portadores de referência à identidade, à ação, à memória dos diferentes grupos formadores da sociedade brasileira”. (BRASIL, 1988, Art. 216).

Lemos (2010) dentro deste pressuposto apresenta Patrimônio Cultural em três categorias de elementos: os pertencentes a natureza e meio-ambiente, remetendo aos recursos oferecidos pela natureza; uma segunda categoria de elementos intangíveis com referencia as técnicas, aos saberes e aos fazeres; a outra categorias faz alusão aos bens tangíveis, isto é, os bens materiais, objetos, artefatos, construções, etc. Com base nestas definições de Lemos (2010) bem como, na legislação federal vigente nos embasamos para analisar as Furnas de Sombrio como um bem cultural local.

\section{FURNAS DE SOMBRIO: ALGUNS APONTAMENTOS}

Atualmente, as Furnas e seu entorno são marcados pela ação antrópica. Dois fatores que se relacionam podem ser atribuídos a isso: primeiro pelo local ser de fácil acesso e segundo por conter um posto de gasolina com lancheria em frente às grutas. Devido a isso, a iniciativa privada faz algumas interferências ${ }^{2}$ no local para torná-lo mais atrativo a visitação. Contudo, nem sempre foi assim, Reitz (1948) em seu livro "Paróquia de Sombrio" escreve sobre as grutas e aponta para um ambiente que nos remete ao natural.

\footnotetext{
${ }^{2}$ Estas interferências consistem em cuidados com o lixo, manuseio da vegetação de entorno das grutas, em alguns momentos o interior da gruta principal foi, em parte, pintado, a segunda gruta foi interligada ao espaço comercial.
} 
Este relato de Reitz (1948) pode ser considerado o relato escrito mais antigo sobre este local, considerando também que a ocupação pós-colonização ${ }^{3}$ vai se adensar na região apenas na segunda metade do século XX (SILVEIRA, 2020). Para Reitz (1948), este complexo de grutas era uma das grandes belezas catarinenses, falando de um tempo aonde as Furnas faziam margem às águas da Lagoa de Sombrio. Observamos sua descrição:

\begin{abstract}
Os seus arredores são admiravelmente belos e recordam saudades a todos que os viram. Amplo plano se extende (sic) ante sua boca, que beija as doces águas da lagoa de Sombrio. Tres (sic) furnas menores, mas talvez mais belas dizem ao viandante que algo de grandioso esta nas proximidades. Verde mata cobre a elevação em cujo seio se conserva uma das principais belezas da natureza barriga-verde, que é tão pródiga na exibição de sua formosura. (REITZ, pg.104)
\end{abstract}

É inegável que as Furnas de Sombrio são exemplos de bens culturais naturais. Contudo, elas também foram resignificadas para o patrimônio religioso - explanarei sobre o assunto a seguir -, desta forma, no decorrer dos anos o ambiente interior da gruta principal, sofreu alterações para comportar o valor que lhe foi atribuído. Em um dos pontos a água de goteja de teto ganhou uma mangueira; o chão de terra batida ganhou cascalho; uma pequena escada de tijolos foi construída para servir de altar; e é notável que em algum momento as paredes rochosas que rodeiam o 'altar' foram pintadas de cal. A seguir podemos observar a entrada da gruta principal na qual se pode perceber imagens religiosas.

\footnotetext{
${ }^{3}$ Consideramos na escrita desde texto o ano de 1500 como marco para a colonização no Brasil. Portanto, após o processo de colonização do território nacional, apenas no século XX a ocupação se adensa na região Sul de Santa Catarina, a isso pode ser atribuído diversos fatores.
} 
Figura 1: Gruta principal, 2011.

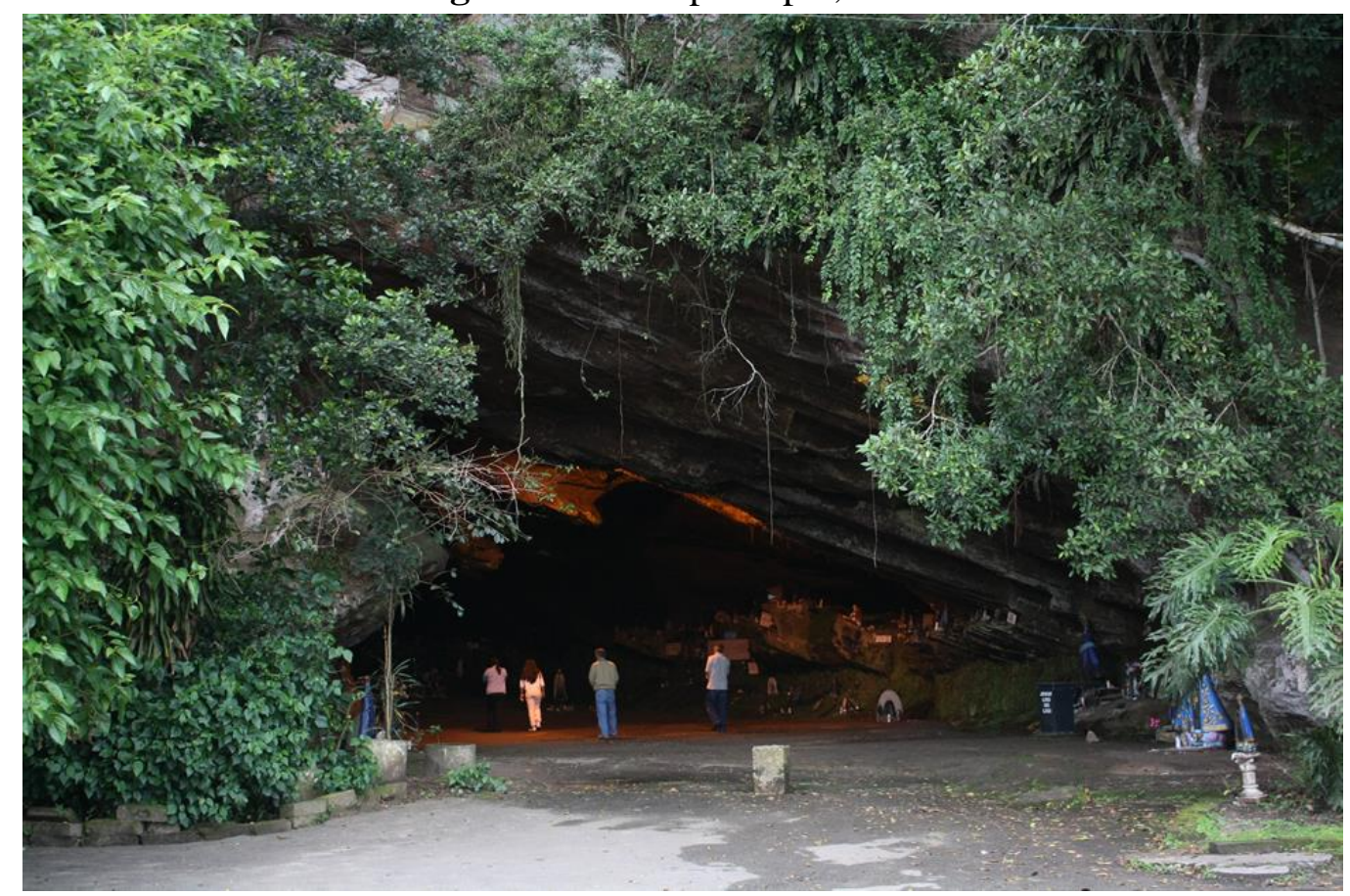

Fonte: Site Cidades do meu Brasil.

Entretanto, no relato de Reitz, percebe-se um ambiente rústico com estalactites, grandes blocos de pedra, musgos e morcegos, um ambiente praticamente sem antrópica. Vejamos mais um trecho de sua descrição.

Ao se entrar nota se uma áureo colorido na superfície das águas. Amplo e profundo é o salão principal. Pesados e duríssimos blocos de pedra estão semeados pelo chão. Aqui serpeia um fio de límpida e fresca água; lá denso tapete de samambaias, selaginelas e musgos se disputam a primazia no avanço pela penumbra a dentro; acolá esvoaçam morcegos, satisfeitos em estarem ao abrigo da luz. Silêncio litúrgico vagueia pelo espaço. (REITZ, pg. 104)

Quando ao exterior das Furnas, atualmente, a lagoa recuou muitos metros, a BR 101 rodovia que corta o país, passa aproximadamente $100 \mathrm{~m}$ da maior gruta. Ao Sul da mesma gruta tem um restaurante, ao norte em anexo a segunda gruta tem uma lanchonete e um posto de gasolina, como mencionado anteriormente. A segunda gruta também sofreu com alterações antrópicas, pode-se dizer que ela foi "decorada" para deixar o ambiente da lanchonete mais agradável. Em contra ponto, Reitz (1948) retrata um ambiente com muitas "figueiras, orquídeas, bromélias e linas". $\mathrm{Na}$ figura 2, a fotografia foi tirada do interior da gruta principal de maneira que é possível observar a paisagem de entorno das grutas na década de 1950. 
Figura 2: Furnas e Lagoa de Sombrio , 1956.

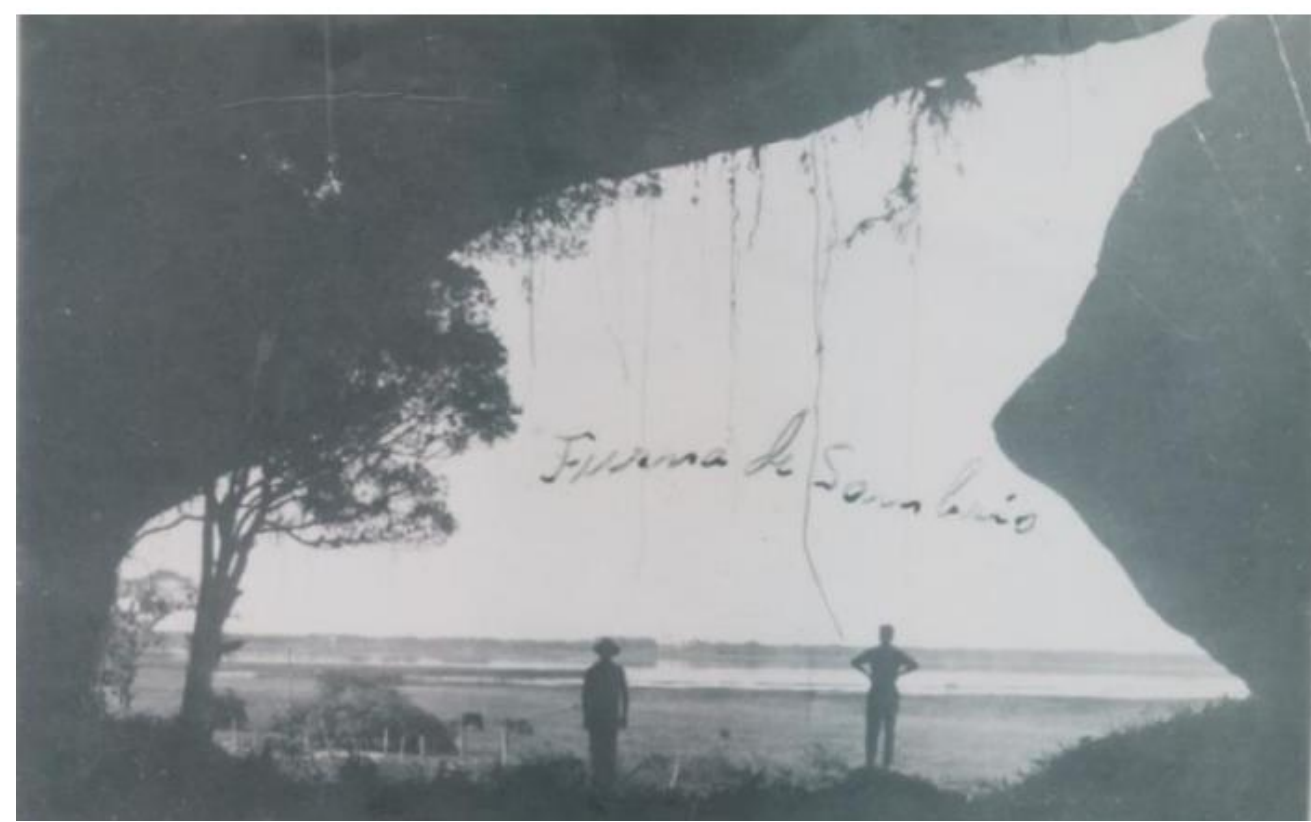

Fonte: Arquivo Digital de Alfredo Ricardo Lucas Lopes.

Lendas sobre as Furnas de Sombrio também são contadas, versam sobre tesouro escondido, histórias que viajantes teriam visto assombrações na entrada da gruta principal, outros afirmavam ter testemunhado o surgimento de bolas de fogo no interior da mesma. Porém, estes relatos são contestados por outros, alegando nunca terem presenciado nada, conta Murara (2000). Pode-se elencar estas histórias como um possível motivo para Manoel Valerim, antigo morador da cidade, colocar a imagem de uma santa na entrada da gruta principal. $\mathrm{O}$ autor analisa que para religiosos o motivo se justifica por ser uma inspiração popular e religiosa da época. Há relatos que naquele tempo qualquer gruta era considerada um local propício para a colocação de uma imagem santificada como forma de louvor.

Se este foi realmente o motivo que levou Manoel Valerim colocar a imagem da Santa não se sabe, mas o reflexo que este ato tem ainda nos dias de hoje é enorme. Muitas outras imagens de santos foram colocadas por pessoas procurando alcançar alguma graça divina. No local, é visível também muitas mensagens de agradecimento, e a água de pinga pela rocha arenítica do teto passou a ser considerada santa.

A fama das Furnas de Sombrio foi longe, facilitada pela BR 101 que foi construída de forma que corta o município sombriense ao meio, já visando o crescimento econômico do mesmo, e talvez já visando este patrimônio natural religioso como um ponto turístico, se considerarmos que a rodovia passa em frente a este bem. 
Sem perder tempo, em meados das décadas de 1950 e 1960, Manoel Valerim aproveitou-se do potencial turístico das Furnas de Sombrio, e fundou o restaurante Furnas. Na figura 3 a seguir podemos ver o restaurante, bem como nos dimencionar quanto a paisagem que circundava das grutas ainda na segunda metade do século XX. A estrada que aparece na horizontal no fundo da imagem, canto esquerdo, posteriormente viria a ser a Br 101, construída entre final da década de 1960 e inicio da década de 1970, assim temos uma data aproximada de quando a foto foi tirada, supõe-se que na ocasião o fotógrafo estava em cima no morro das cavidades rochosas. Observe:

Figura 3: Vista geral da área, segunda metade do século $\mathrm{XX}$.

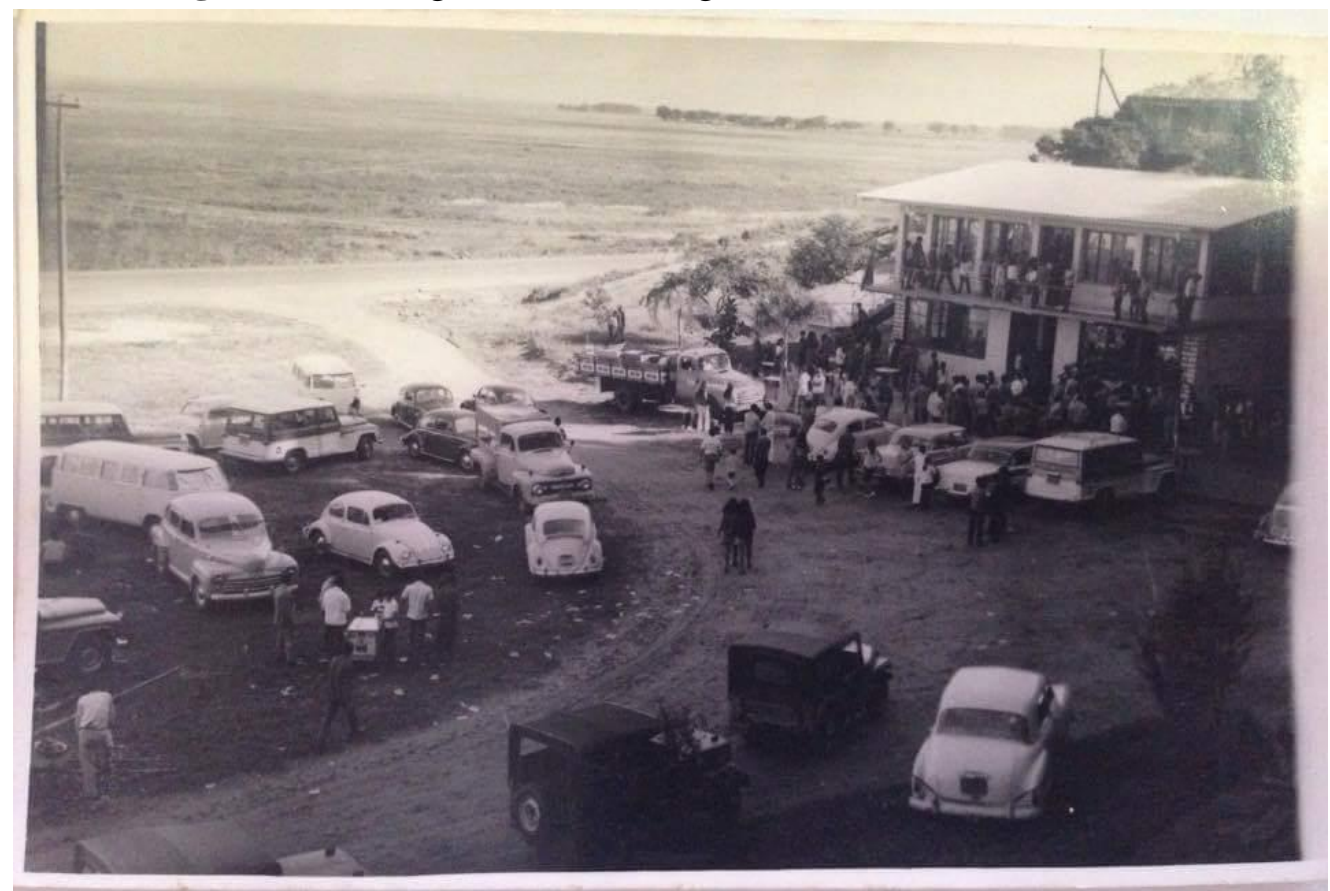

Fonte: Arquivo particular Valmoré Colares

Anos mais tarde foi construído uma lanchonete e um posto de gasolina praticamente em anexo a segunda gruta. Podemos relacionar este fato a disseminação das Furnas como um ponto turístico referente a patrimônio cultural, natural e religioso, pois ao parar para abastecer, lanchar e descansar da viagem as pessoas tomam conhecimento do valor atribuído ao local. Muitos acabam fazendo preces e pedidos, outros levam um pouco da água que goteja pelo teto da gruta a considerando benta/santa, conforme podemos observar in loco durante a visita ao local

Cardoso (2011) em sua hipótese confirma a visão empreendedora de Valerim ao colocar a imagem na gruta, mas visando em primeiro momento atrair 
visitantes para o seu restaurante explorando as propriedades medicinais de um lodo negro encontrado no interior da gruta. Murara analisa esta questão:

\begin{abstract}
Manoel Valerim também preocupou-se em mandar fazer exames técnicos a respeito da lama negra encontrada dentro da furna principal e que alguns diziam ter poder medicinal. Foi coletado material e enviado para São Paulo e tempos depois um laudo atestava tratar-se de uma composição de algas marinhas com propriedades aplicadas na dermatologia (tratamento de pele) [...] Várias pessoas que vivem até hoje afirmam ter lido este laudo, mas o documento perdeu-se no tempo. (MURARA, 2000, pg. 2)
\end{abstract}

A venda de produtos intitulados milagrosos estimulou ainda mais a crença religiosa no local, com o passar dos anos as imagens de santos foram se multiplicando, assim como as placas de agradecimento. Cardoso (2011) analisa que no mês de agosto de 2010, num domingo a Furna principal recebe cerca de 380 pessoas, sendo que no verão esse numero é maior. O Resultado disso é a alteração e degradação desta gruta, que atualmente já tem dois altares para colocação de santos.

\footnotetext{
Possui dois altares para colocação de imagens, um bem ao fundo e o outro entre esse primeiro e a entrada do segundo salão. Diversas imagens sacras, além de outras oferendas, estão depositadas nesses altares e praticamente não há mais espaço para mais oferendas. A lateral direita de quem entra na furna também contém diversas imagens, desde a entrada até os fundos, algumas no chão e outras mais acima na camada de rocha mais dura que se sobressalta em quase toda parede. (CARDOSO, 2011, pg. 34)
}

As Furnas e Sombrio apesar de serem um bem natural da cidade, logo pertencendo a todos e a cuidado de todos, acabou por somar a iniciativa privada com o restaurante inicialmente, e o posto de gasolina atualmente. É incontestável a contribuição deste local na história da região e o valor atribuído a ele pela população local e visitantes, que vem de longe acreditando no valor religioso da gruta e na monumentalidade desde patrimônio. Fato que deveria ser considerado pelo poder público, de forma que gerasse uma intervenção para proteção deste bem.

Segundo Cardoso (2011), este bem sofre um impacto ambiental causado pelas práticas religiosas. As pichações e o lixo jogado pelos visitantes se tornam problemas menores em relação ao impacto ambiental pelo acumulo de oferendas. Ele analisa que muitas das estatuetas estão destruídas pelo tempo ou mesmo depredadas. Sendo que algumas destas foram fixadas nas paredes da caverna com cimento.

A furna principal tem um segundo salão, menor, que encontra-se bloqueado para acesso dos visitantes por uma tela de metal. Dele é retirado o lodo que segundo a 
crença popular tem propriedades medicinais. Para Cardoso o fechamento deste segundo salão é indevido já que o artigo 225 da Constituição federal Brasileira defende que:

Todos têm direito ao meio ambiente ecologicamente equilibrado, bem de uso comum do povo e essencial à sadia qualidade de vida, impondo-se ao Poder Público e a coletividade o dever de defende-lo e preservá-lo para as presentes e futuras gerações. (CARDOSO, 2011, pg 41)

Cardoso (2011) aponta ainda que seguidores de crenças que não cultuam imagens, e não praticam oferendas podem sentir-se inibidos de visitar a Furna principal devido às estatuetas.

De acordo com o caderno de documentos: Cartas Patrimoniais (IPHAN, 1995), bens naturais que tem interesse cultural e até estético, devem ser preservados e até restituídos se necessário, que é o caso da primeira gruta do complexo das furnas de Sombrio.

Para os efeitos da presente recomendação, entende-se por salvaguardar da beleza e do caráter das paisagens e sítios a preservação e, quando possível, a restituição do aspecto das paisagens e sítios, naturais, rurais ou urbanos, devido a à natureza ou à obra do homem, que apresentam um interesse cultural ou estético, ou que constituem meios naturais característicos. (Cartas Patrimoniais, p. 98)

Cabe salientar que uma das formas do reconhecimento do Patrimônio Histórico é o inventário que consiste em um dos primeiros passos para a proteção de um bem considerado patrimônio. Posteriormente através do tombamento às leis preveem não apenas a manutenção do bem como a preservação de seu entorno para que não haja descaracterização do mesmo.

\section{CONSIDERAÇÕES FINAIS}

Visto a importância das Furnas de Sombrio para localidade pode-se dizer que ela se enquadra como um patrimônio cultural natural local, principalmente analisando a partir da perspectiva apontada por Gonçalves (2002). Ele analisa que no Brasil o significado de patrimônio natural passou a ser entendido como uma conquista da sociedade, o patrimônio natural integra o cultural com um significado ligado às práticas sociais e à memória coletiva; portanto, um patrimônio natural que, antes de tudo, faz parte da vida humana e não algo que a ela se opõe. Nesta visão, as Furnas como espectadora do processo civilizatório da localidade, testemunha de religiosidade de um povo, e mais que isso, participante das relações econômicas, sociais, políticas e 
principalmente religiosas, ou seja, as relações culturais, é um potencial patrimônio que precisa de proteção.

Como todo patrimônio cultural, as Furnas de Sombrio deveriam ser preservadas, mas no Brasil, segundo dados do Iphan, não tem legislação específica seguindo critérios da UNESCO quanto às paisagens culturais. Desta forma, as paisagens com funções ecológicas ficam protegidas pela legislação de conservação da natureza, sob a guarda de órgãos ambientais. Quando são paisagens ambientais culturais o Ibama e o Iphan respondem pela área. Mas, neste processo de divisão entre o cultural e ambiental, o patrimônio natural sofre com as degradações. Isso se torna claro quando associamos a situação das Furnas que além da degradação, praticamente integra um ambiente privado.

Na sociedade atual, é possível observar uma diferença aos valores elencados a cada tipo de patrimônio, o cultural transcende ao natural, tanto que o lado ambiental das Furnas é quase esquecido perto do religioso. Contudo, a luta para a preservação de bens culturais é árdua. Refletimos então, sobre a preservação de bens naturais, a dificuldade é ainda maior, nesta sociedade que tem a natureza como serva, que desconsidera a diversidade de fauna e flora. Silvia Helena Zanirato (2010) aponta que a biodiversidade raramente aparece nas discussões patrimoniais, a natureza só entrou nestas discussões por valores estéticos e não pela sua importância intrínseca.

As Furnas de Sombrio não devem ser defendidas apenas como um patrimônio natural, mas também, histórico-cultural. É preciso a conscientização da população local, e um projeto que trabalhe educação patrimonial nas escolas para que as novas gerações tenham outra perspectiva com este e outros bens culturais. Para os visitantes, instruções sobre o histórico do local, assim como de bom uso do ambiente. E ainda uma revitalização da principal gruta.

Mas, antemão á isso é necessário que o governo municipal, usando de suas atribuições defina que as Furnas não fazem parte do patrimônio privado, não podendo haver telas privando o acesso das pessoas a totalidade de bem. Da mesma forma, se 'pertencesse' ao privado este teria obrigação de zelar pelas boas condições do ambiente. O que não acontecesse atualmente, o bem não recebe respaldo nem municipal e nem da empresa que usufrui do bem como atrativo, alegando que a pretensão é manter o local mais natural possível.

É preciso que a comunidade reaja, tome conhecimento da beleza natural desde local e pressione o poder público a tomar uma iniciativa, de forma que deixe o 
ambiente mais agradável e menos macabro, acessível a todo tipo de público. Afinal esta localidade faz parte da história regional e nacional.

\section{REFERÊNCIAS:}

CARDOSO. Pablo. Impacto ambiental causado por práticas religiosas nas furnas de Sombrio/SC. Criciuma, 2011.

CARTAS PATRIMONIAIS. Caderno de Documentos nº 3, Brasília, IPHAN, 1995.

GONÇALVES, J. R. S. Monumentalidade e cotidiano: os patrimônios culturais como gênero de discurso". In: OLIVEIRA, L. (org) Cidade: História e Desafios. Rio de Janeiro: Editora FGV, 2002. p.108-123.

IPHAN. O Patrimônio natural no Brasil. Disponivel em: <portal.iphan.gov.br/baixaFcdAnexo.do ?id=418:> Acesso em: 26/11/2014.

MURARA, Marcial David. Furnas de Sombrio. Biblioteca Pública Municipal Cônego João Reitz Sombrio - SC, 2000. 3p.

REITZ, Raulino Pe. Paróquia de Sombrio (ensaio de uma monografia paroquial). Edição comemorativa, 1938-1948. Sombrio: Paróquia Santo Antônio de Pádua, Ed.1988, 194p.

ZANIRATO, S. H. O patrimônio natural do Brasil. Projeto História $n^{\circ} 40$, junho de 2010, pp. 127-145. 